\title{
Computationally efficient method of simulation of an electric drive impact on the power grid
}

\author{
RySZARD BENIAK, ARKADIUSz GARDECKI \\ Opole University of Technology \\ Faculty of Electrical Engineering, Automatic Control and Computer Science \\ 45-272 Opole, Sosnkowskiego 31, Poland \\ e-mail: \{r.beniak/a.gardecki\}@po.opole.pl
}

(Received: 22.10.2012, revised: 19.11.2012)

\begin{abstract}
This paper presents a computationally efficient method for modelling an impact of the converter drive on the power grid. The formalized variable structure method (FVSM) allows for comprehensive studies of the effect on the power grid and examining the relation between this effect and the number of drive and feeding line parameters. In order to obtain a comprehensive model along with the model of the power grid, the parameters that are applied originate from a drive of a coal-fired power station. These parameters have been determined based on assessment and estimation. The estimation process was conducted with the aid of a model that allows for the commutation of power electronic elements. The authors confirmed that the model was correct by comparing empirical and theoretical voltage and current waveforms. Harmonic content of the voltage and current in the power grid which feeds the drive are considered to be the measure of the converter drive impact on the power grid. The standard method for the reduction of a harmonic content in the voltage and current involves the application of line reactors and distribution or converter transformers. As an example, the authors determine the impact of the drive on the power grid with respect to the adopted parameters of the line reactor. This example presents FVSM abilities with regard to simulation of complex systems that contain power grid components and converter drives.
\end{abstract}

Key words: electric drive, converter system model, power grid

\section{Introduction}

Reduction of interference in power grids has been for environmental reasons growing in importance for policymakers. At the same time, the simulation research aims at attaining the best possible configuration of the drive system along with feeding grid. Thanks to this approach the authors can omit problematic and sometimes impossible measurements. The purpose of this paper is to show that it is possible to develop variable structural method of simulations that allows for precise modelling of a drive and its impact on the power grid. Such modelling enables selecting a quasi-optimum combination of the electric drive and the power 
grid components. Such selection has been motivated with numerous simulations performed over the entire drive with respect to a motor load and parameters of the power grid. This method (Fig. 1) allows for selecting such parameters of the supply grid that the impact of the drive on the grid is minimized.

The measurement results presented in the paper are based on performance tests of a system consisting of a district heating pump in a power plant [1]. To verify if the identified drive parameters have been identified correctly, the authors compared the theoretical and empirical waveforms (Section 6).

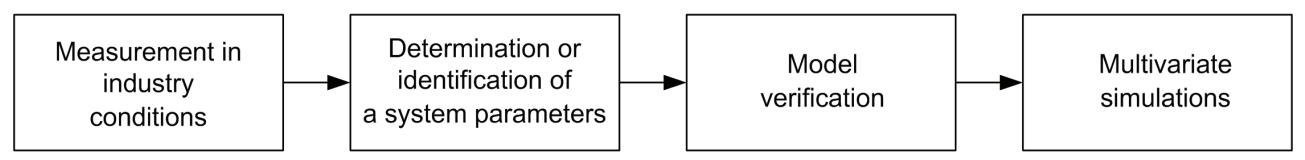

Fig. 1. An example methodology of mathematical modelling of converter drives

Within the area of numerical tests, this paper focuses on the effect of a converter drive on the supply network with a particular emphasis on the effect of the higher harmonics. The adopted measure of this effect is associated with Total Harmonic Distortion of the voltage $\left(T H D_{U}\right)$ and current $\left(T H D_{I}\right)[2,3]$. The analyzed converter system is controlled with the scalar pulse-width modulation method (PWM) [4, 5]. This paper presents subsequently: a short description of the formalised variable structure method, the model of the electric drive and a study on the conformity of empirical and theoretical results. Finally, the authors present the effect of the load and the line reactor in the supply grid on THD coefficients.

\section{Formalised variable structure method}

The model developed for the drive system simulation bases on the formalised variable structure method (FVSM). Its algorithm follows a method of mesh analysis and starts its operation for a system of differential equations which define all branches in a drive and supply network:

$$
\boldsymbol{u}_{B}=\frac{d}{d t}\left(\boldsymbol{L}_{B} \boldsymbol{j}_{B}\right)+\boldsymbol{R}_{B} \boldsymbol{j}_{B}+\boldsymbol{v}_{B}
$$

where: $\boldsymbol{u}_{B}$ is the vector of branch voltages, $\boldsymbol{j}_{B}$ is the vector of branch currents, $\boldsymbol{L}_{B}$ is the inductance matrix, $\boldsymbol{R}_{B}$ is the resistance matrix, $\boldsymbol{v}_{B}$ is the equivalent vector of voltage sources. The initial set of differential equations is formally reduced into their final form by means of matrices $\boldsymbol{P}$ and $\boldsymbol{D}$. A detailed description of the method of generating these matrices is presented in [6]. The branch equations are transformed by means of $\boldsymbol{D P} \boldsymbol{u}_{\boldsymbol{B}}=\mathbf{0}$, thus creating closed loops and $\boldsymbol{j}_{B}=\boldsymbol{P}^{T} \boldsymbol{D}^{T} \boldsymbol{i}_{L}$ by eliminating all elements which do not form the current state variables from the vector of branch currents. By applying the above substitutions, the authors obtain the final form of the state differential equations: 


$$
\underbrace{D P u_{B}}_{0}=\frac{d}{d t} \underbrace{D P L_{B} P^{T} D^{T}}_{L_{L}} i_{L}+\underbrace{D P R_{B} P^{T} D^{T}}_{R_{L}} i_{L}+\underbrace{D P v_{B}}_{v_{L}} .
$$

The calculation of voltages across non-conducting branches [6] is performed by: assigning the minimal graph tree, calculating the node potentials for tree nodes and calculating the differences between node potentials. The tree is obtained by means of a modified nearestneighbour algorithm [7], for which the total number of operations is equal to $O\left(|N|^{2}\right)$, where $N$ is the number of the graph nodes.

The potentials of nodes located outside the actual graph are calculated in the following way:

$$
\boldsymbol{V}=\boldsymbol{G}^{-1} \boldsymbol{J}
$$

where: $\boldsymbol{V}$ is a vector of calculated node potentials, $\boldsymbol{G}$ is a substitute matrix defining electrical conductivities and $\boldsymbol{J}$ is a vector defining virtual node currents, which flow to the nodes. The size of the vector $\boldsymbol{V}$ is equal to the number of nodes $j$, which are situated outside the current graph structure: $\boldsymbol{V}^{T}=\left[V_{x 1}, \ldots, V_{x j}\right]$. The matrix $\boldsymbol{G}$ takes the following form:

$$
\boldsymbol{G}=\left[\begin{array}{cccc}
\sum_{i=1}^{j} G_{x 1, x i}, & -G_{x 1, x 2}, & \ldots, & -G_{x 1, x j} \\
-G_{x 2, x 1}, & \sum_{i=1}^{j} G_{x 2, x i}, & \ldots, & -G_{x 2, x j} \\
\vdots, & \vdots, & \ddots, & \vdots \\
-G_{x j, x 1}, & -G_{x j, x 2}, & \ldots, & \sum_{i=1}^{j} G_{x j, x i}
\end{array}\right]
$$

while the form of the element $G_{k, i}$ depends on the elements situated in the branch connecting the $k$-th and $i$-th node:

- for inductance $G_{k, i}=\left(L_{k, i}\right)^{-1} \delta t$,

- for resistance $G_{k, i}=\left(R_{k, i}\right)^{-1}$,

- for both inductance and resistance $G_{k, i}=\left\{1-\exp \left[\left(-\left(R_{k, i} / L_{k, i}\right) \delta t\right]\right\} / R_{k, i}\right.$ where $\delta t$ is the time step depending on calculation process. The vector $\boldsymbol{J}$ takes the following shape:

$$
J=\left[\begin{array}{cc}
\sum_{k=1, k \neq x i}^{b}\left(V_{k}+E_{k, x 1}\right) G_{k, x 1}-\sum_{i=1, i \neq x 1}^{j}\left(E_{x 1, i}\right) G_{x 1, i} \\
\sum_{k=1, k \neq x i}^{b}\left(V_{k}+E_{k, x 2}\right) G_{k, x 2}-\sum_{i=1, i \neq x 2}^{j}\left(E_{x 2, i}\right) G_{x 2, i} \\
\vdots \\
\sum_{k=1, k \neq x i}^{b}\left(V_{k}+E_{k, x j}\right) G_{k, x j}-\sum_{i=1, i \neq x j}^{j}\left(E_{x j, i}\right) G_{x j, i}
\end{array}\right]
$$

where $V_{k}$ is the potential of $k$-th tree node and $E_{k, x i}$ define voltages of voltage sources and voltages across the capacitors in branches connected $k$-th and $x i$-th nodes. 
The calculation of potentials allows for evaluating the voltages across the branches that are not contained in the current graph. At least one end of these branches is attached to the node situated outside the actual graph tree.

\section{Model of the drive system}

In research involving multivariate simulation it is important to select a drive model according to the range of results that should be gained from simulations. An equally important goal of such adaptation is to gain conformity between the results of measurements and simulations. The authors adopt an extended model of the converter drive system [1]. This model (Fig. 2) combines the supply grid with the rectifier and includes commutation process in the rectifier and inverter.

The model of the drive has been modelled with formal variable structure method $[6,8]$. It allows for an efficient calculation of voltages and currents determining the phenomena associated with switching of power electronic part of the drive. The model selects an appropriate configuration of the inverter with a PWM scalar control algorithm [4, 5]. For FVSM, branches containing non-conducting power electronic elements and branches for which at least one end is not attached to the other branch are temporarily removed from the structure of the model. In Figure 2, branches containing non-conducting power electronics elements during commutation of transistor T1 with diode D4 are marked in black.

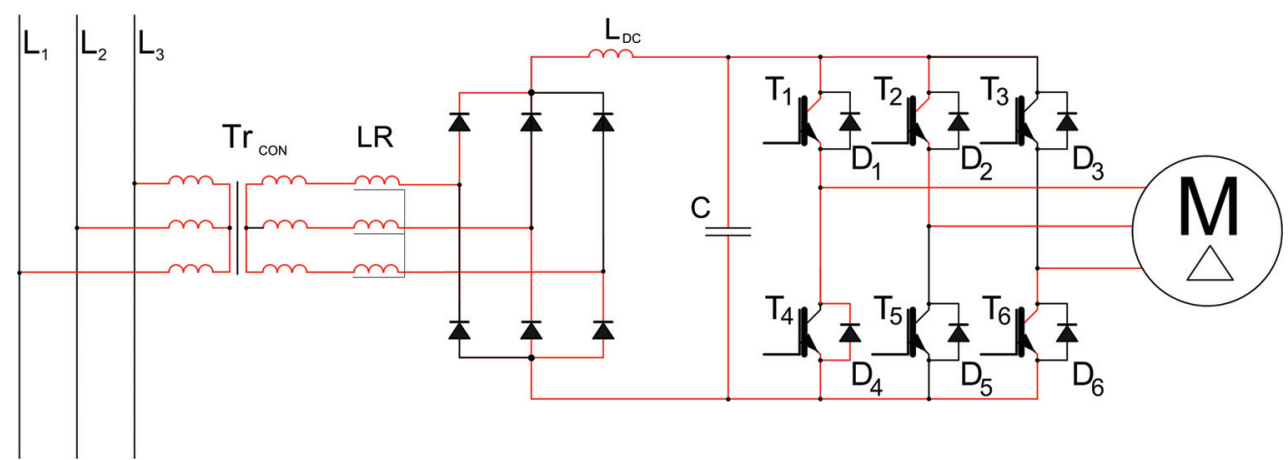

Fig. 2. Diagram of a complete model of the drive (red lines are an example of a conducting structure)

Figure 3 exemplifies the commutation between transistor T1 and diode D4 in the inverter (a section of the time curve). This allows for effective modelling of phenomena occurring in the inverter during its operation and modelling of energy losses resulting from these phenomena.

When developing the mathematical model of an induction squirrel-cage motor the authors made a simplifying assumption as in [4]. Monoharmonic model of an induction motor [4] with variable resistance of the rotor has been modeled in UVW coordinates with the rotor equations transformed into a two-axial system and the untransformed stator equations. The parameters applied to the load simulation result from the actual characteristics of the pump. 

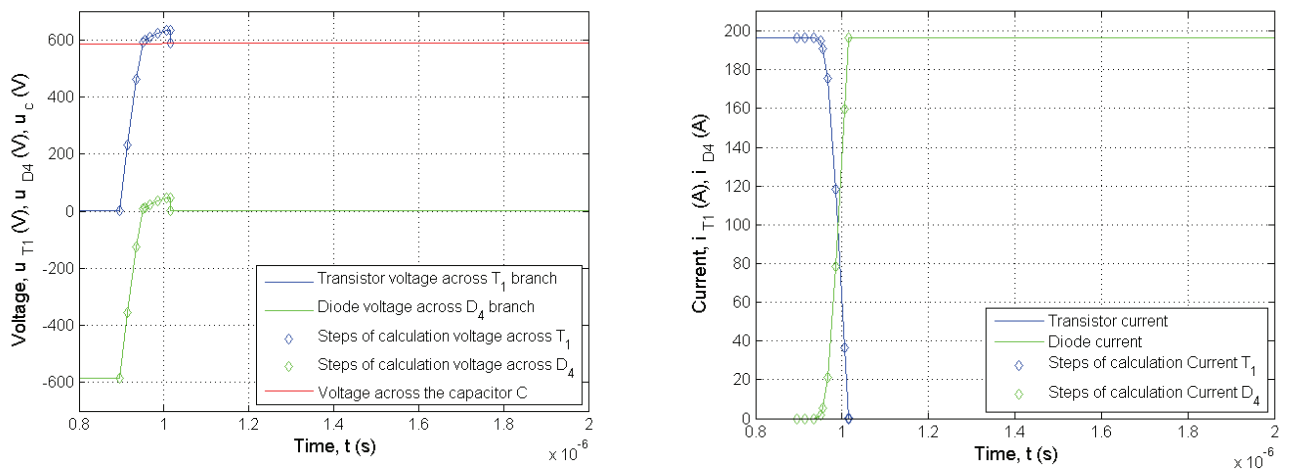

Fig. 3. Voltages and currents in commutation yielded from simulation (transistor current $\mathrm{T}_{1}$ transit through a diode $\left.\mathrm{D}_{4}\right)\left(f_{c}=3.5 \mathrm{kHz}\right)$

The system of differential equations has been solved with the Adams method with a variable step using DIFSUB procedure [9], with its steps controlled by an external module.

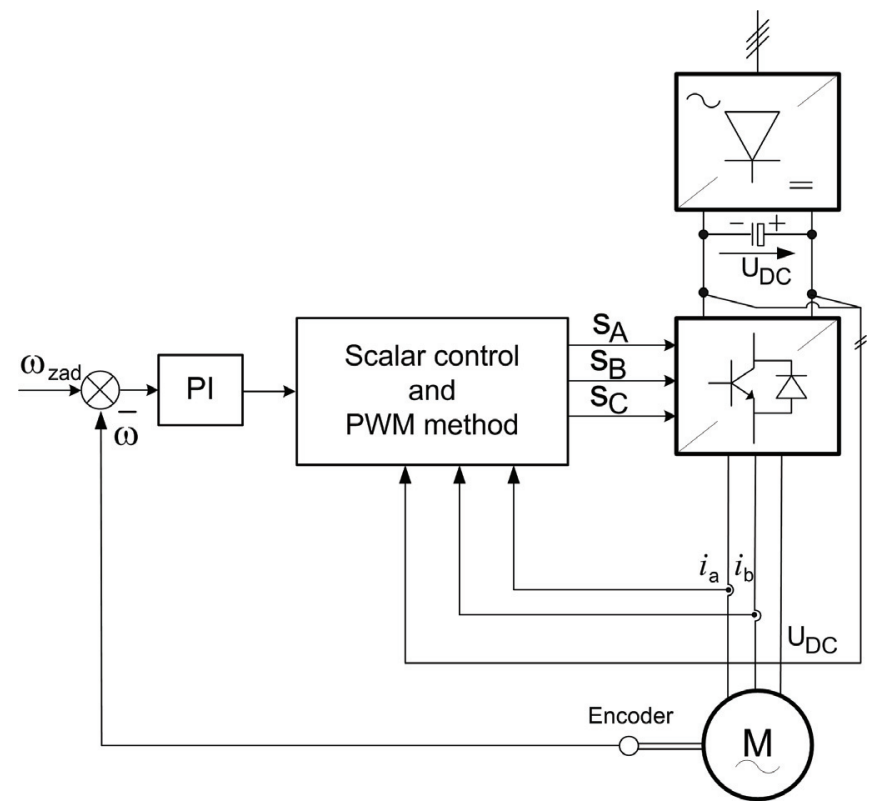

Fig. 4. Block scheme of the scalar control method applied in the simulation

In the cases of the interest, the model of the inverter control system realizes the scalar PWM control. The control algorithm applied by the authors decreases the frequency at which the power electronic part of the drive is switched on, which helps reduce losses in the inverter. 


\section{Comparison of the formalised variable structure method with the steady structure method}

Models that apply steady structure method demonstrate different properties compared to models that apply variable structure method. In the case of modelling of the drive from Figure 2 with a steady structure method for data gained on the basis of measurement the authors obtain: determinant of the inductance matrix equal to around $7.6 \cdot 10^{-52}$, time constants of the power electronic elements in non-conducting state within the range from $2 \cdot 10^{-10}$ to $1 \cdot 10^{-13}$ and 24 differential equations that define the drive. For the variable structure method, the determinants of the matrix vary within the range from $1.4 \cdot 10^{-13}$ to $3 \cdot 1 \cdot 10^{-24}$ and the number of differential equations in the model is within the range from 10 to 13 .

This points to the advantage of the FVSM. For FVSM, the authors obtain a smaller number of differential equations and a higher determinant of the inductance matrix. Due to the time constraints, for numerical integration of differential equations in the FVSM we can apply the Adams method [10]. Meanwhile, the steady structure method requires the Gear method for this purpose $[9,10]$. The Gear method requires determining the Jacobian (mostly in numerical way) in the form (6) which increases the computation time significantly.

$$
\boldsymbol{J}[\boldsymbol{f}(\boldsymbol{x}, \boldsymbol{t}), \boldsymbol{x}]=\frac{\partial f_{i}\left(x_{j}, t\right)}{\partial x_{j}} ; \quad i, j \in\{1, \ldots, n\},
$$

where $\mathrm{n}$ is the number of differential equations.

\section{Determination of drive parameters in industrial conditions}

In order to gain information necessary for the model of the drive, it is necessary to be familiar with the electromechanical parameters specific for the tested object. One of the ways to obtain unknown parameters is to measure the selected specific operating states of this object. In order to identify the parameters, the authors conducted measurements at the input of the rectifying bridge of the frequency converter and the output of the inverter section of the converter (Fig. 5). In addition, the authors registered the waveform of the angular speed of the drive (Fig. 6). The measured system did not contain line voltage reactors. In industrial conditions, it is not always possible to carry out all required measurements.

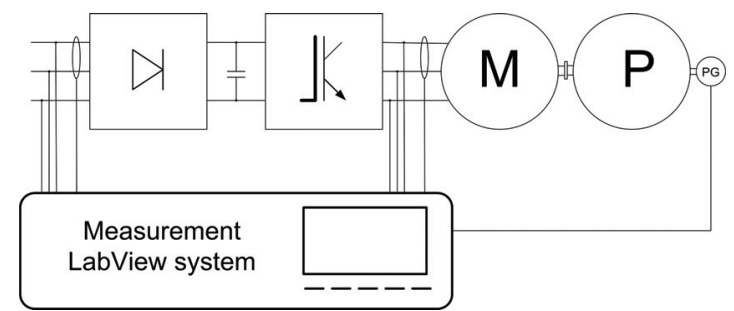

Fig. 5. Diagram of the measurement system 
It is often necessary to restrict the range of measurements to selected loads and possible manipulations in the settings of the control system. In order to reduce the number of bothersome measurements, after conformity between theoretical and empirical waveforms is established, it is possible to analyze the impact of parameters and various settings on the control system based on simulations. This concerns particularly the impact of the converter part of the drive on the motor and the power grid.

Some parameters necessary for developing a mathematical model of the system are derived from manufacturers' data of the motor, transformers, cables and converter. The other parameters are obtained from the estimation. The estimation is based on measurements of angular speed and the input and output currents and voltages of the frequency converter. Figure 5 presents the system applied in the measurements consisting of two cards NI 6133 [11]. It provides a registration of analogue signals in 16 channels with the sampling frequency of $400 \mathrm{kHz}$.

In the examined drive, an induction motor type SEE 355ML with the power of $315 \mathrm{~kW}$ drives [12] a district heating pump 20W39MX with the rated capacity of $\mathrm{Q}=550 \mathrm{~m}^{3} / \mathrm{h}$. During the measurements the values of instantaneous voltages and currents are recorded at the input and output of a converter system together with the angular motor speed. The measurements were conducted with the frequency of $400 \mathrm{kHz}$. The start-up and steady state of the drive was recorded. Exemplary results in the steady state are presented in Figures 7-9.

Estimation of system parameters is divided into two steps - previous and final. The starting parameters of the motor in the final step were initially adopted on the base of the previous estimation. This estimation was made for points specific to: the start-up torque, the maximum (critical) torque, the rated torque, the value of the start-up current, the current in the rated conditions and the value of the rated angular speed. Additionally, the values of SEE 355ML motor's moment of inertia and 20W39MX pump's moment of inertia were adopted from manufacturers' data together with data regarding loads corresponding to the steady state of the pump.

\section{Comparison of data from simulations and measurements}

The aim of simulations is to illustrate the behaviour of an actual drive and to apply this model for testing, with a number of alternatives. An example of such testing is determination of a drive load and the effect of inductance in the feeding grid on the spectrum of voltage and current harmonics, and efficiency of a drive. The authors attained the conformity of the results by comparing the empirical and theoretical waveforms. To assess the impact of the converter drive on the power grid, the authors applied $T H D$ coefficient. Additionally to verify the economic effectiveness, the authors assessed the efficiency $\eta$ of a converter drive system (Table 1).

The Figures 6-9 present a comparison between the theoretical and empirical results. This comparison involves sections of voltage and current waveforms for the converter under the assumption of the carrier wave frequency equal to $f_{c}=3.5 \mathrm{kHz}$. Note that Figures 6-9 show that there is a very good conformity of the presented results. 


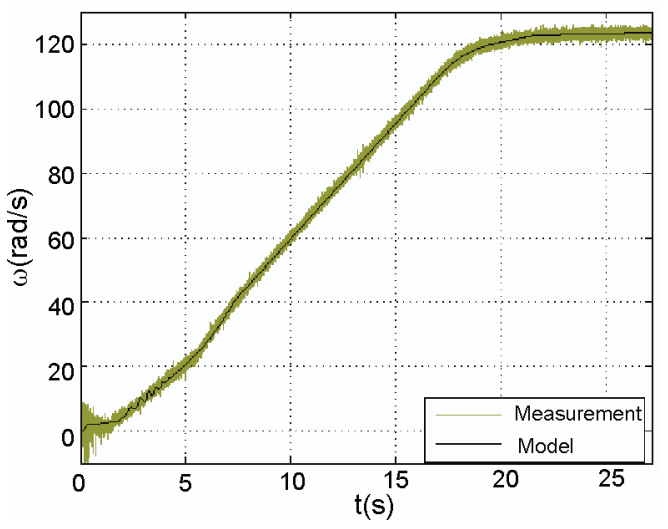

Fig. 6. Comparison of the angular speed waveforms during the start-up

a)

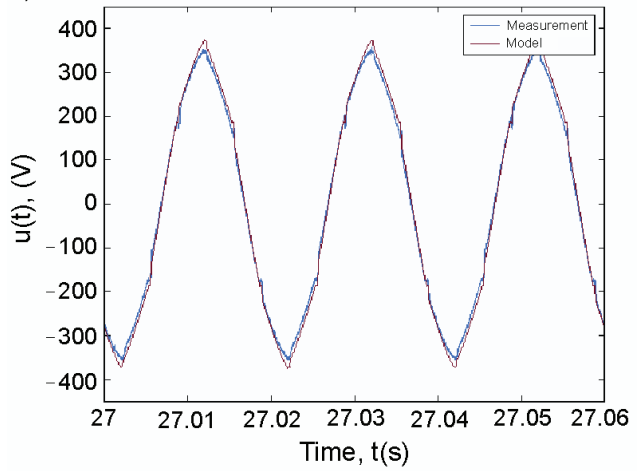

b)

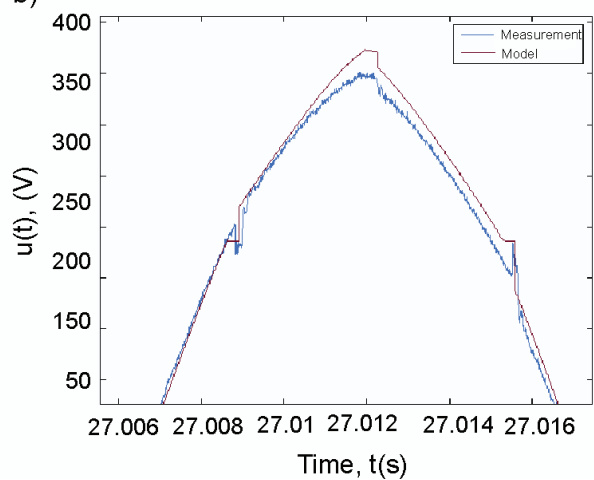

Fig. 7. Comparison of sections of voltage waveforms $u_{L I}$ (a) at the input of converter system $\left(f_{c}=3.5 \mathrm{kHz}\right)$ and its details (b)

a)

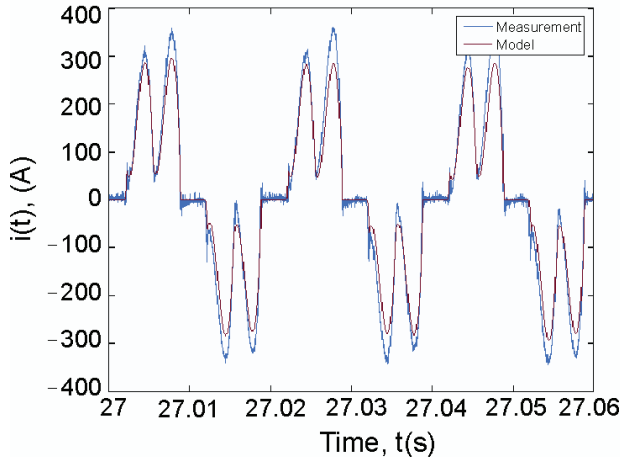

b)

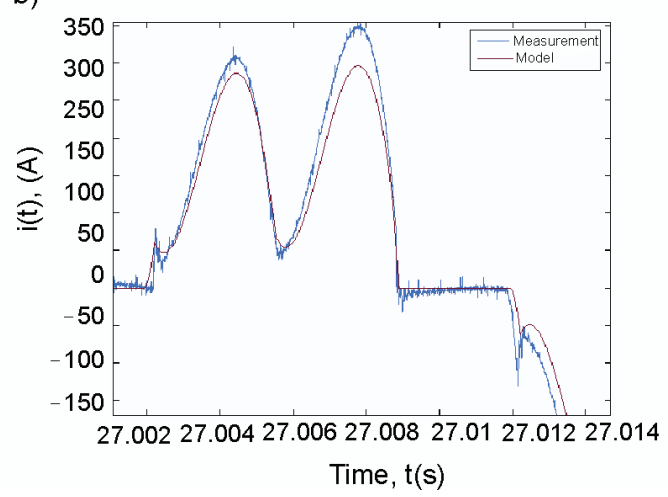

Fig. 8. Comparison of sections of current waveforms $i_{L l}$ (a) at the input of converter system $\left(f_{c}=3.5 \mathrm{kHz}\right)$ and its details (b) 
a)

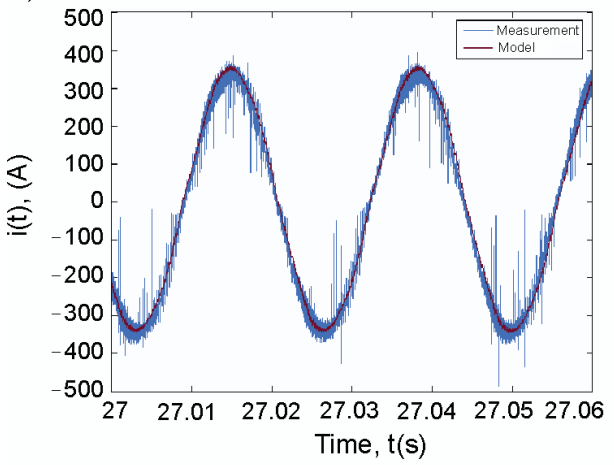

b)

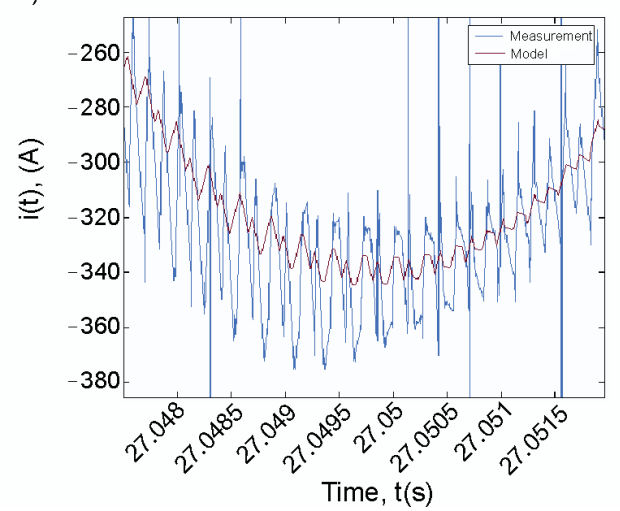

Fig. 9. Comparison of sections of current waveforms $i_{L I}$ (a) at the output of converter system $\left(f_{c}=3.5 \mathrm{kHz}\right)$ and its details $(\mathrm{b})$

Based on the empirical current and voltage waveforms at the input and output of the inverter, the authors calculated the efficiency of the converter section of the drive along with the content of higher harmonics $T H D$ in voltages and currents (Table 1).

Table 1. Summary of selected parameters regarding quality of operation of the drive for carrier wave frequency of $f_{c}=3.5 \mathrm{kHz}$

\begin{tabular}{l|c|c|c}
\hline \multicolumn{1}{c|}{ Measurement } & $T H D_{I}[\%]$ & $T H D_{U}[\%]$ & $\eta$ \\
\hline $\begin{array}{l}\text { Rectifier } \\
\text { supply }\end{array}$ & 60.24 & 6.60 & \multirow{2}{*}{0.977} \\
\cline { 1 - 2 } Motor supply & 6.02 & 8.48 & \\
\cline { 1 - 2 } Model & $T H D_{I}[\%]$ & $T H D_{U}[\%]$ & $\eta$ \\
\hline $\begin{array}{l}\text { Rectifier } \\
\text { supply }\end{array}$ & 57.84 & 6.07 & \multirow{2}{*}{0.987} \\
\cline { 1 - 2 } Motor supply & 5.56 & 7.89 & \\
\hline
\end{tabular}

Note that Table 1 provides further evidence of a good conformity of the empirical and theoretical results, both in terms of level of higher harmonics as well as overall efficiency.

\section{An example of an application of the variable structure model to multivariate simulations}

The model of the drive presented in Section 3 (Fig. 2) has offered a possibility to analyse the impact of inductance and resistance of the feeding grid and motor load on the content of higher harmonics in the supply voltage and current. Even though the example presented in Section 3 might appear conceptually simple, the model can be easily augmented with further 
components. For example, the line reactor to the structure is added by including its parameters in the appropriate branch. FVSM will generate the necessary system of differential equations automatically (2).

The model applied in the calculations (Fig. 10), involves the feeding grid of the rectifier accounting for the parameters of the distribution transformer, cables [13, 14] and network transformer [15] as well as line reactors [16]. The model of the frequency converter includes the commutation phenomena in the rectifier and the inverter.

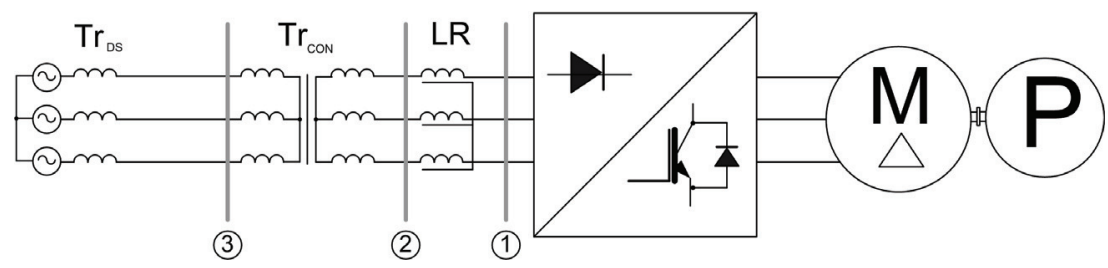

Fig. 10. Model of the drive and power grid with marked cross sections

Table 2. Line reactors parameters

\begin{tabular}{l|c|c|c|c|c}
\hline $\operatorname{Par}_{\mathrm{i}}(1)$ & 0 & 1 & 2 & 3 & 4 \\
\hline $\mathrm{L}(\mathrm{mH})$ & - & 0.016 & 0.032 & 0.048 & 0.064 \\
\hline $\mathrm{R}(\mathrm{m} \Omega)$ & - & 0.56 & 1.23 & 2.29 & 3.59 \\
\hline \multicolumn{7}{c}{,$-"$ mean no line reactors added } \\
\hline
\end{tabular}

Table 3. Selected parameters of the equivalent diagram of the drive

\begin{tabular}{c|c|c|c}
\hline \multicolumn{2}{c|}{ Short-circuit power } & \multirow{2}{*}{$\begin{array}{c}\mathrm{L}_{\mathrm{DC}} \\
(\mathrm{mH})\end{array}$} & $\begin{array}{c}\mathrm{C} \\
(\mathrm{mF})\end{array}$ \\
\cline { 1 - 2 } $\begin{array}{c}\text { Step-down } \operatorname{Tr}_{\mathrm{DS}}, \\
\text { (MVA) }\end{array}$ & $\begin{array}{c}\operatorname{Tr}_{\mathrm{CON}} \\
(\mathrm{MVA})\end{array}$ & & \\
\hline $\mathrm{S}_{\mathrm{SC}}=230$ & $\mathrm{~S}_{\mathrm{SC}}=16$ & 0.086 & 8 \\
\hline
\end{tabular}

The THD coefficient forms a synthetic expression that determines the content of higher harmonics in the supply voltage and current. This is the quotient of the effective harmonics to the effective value of the fundamental harmonic [2] of the voltage:

$$
T H D_{U}=\frac{\sqrt{\sum_{n=2}^{40} U_{n}^{2}}}{U_{1}} 100 \%,
$$

and for the currents it is expressed as:

$$
T H D_{I}=\frac{\sqrt{\sum_{n=2}^{40} I_{n}^{2}}}{I_{1}} 100 \% .
$$


The harmonics were computed based on the Fourier's formula for periodic functions [5]. Table 4 presents mean values (calculated from all phases) of $T H D_{U}$ and $T H D_{I}$ coefficients in relation to additional line reactor parameters in the power grid and motor load.

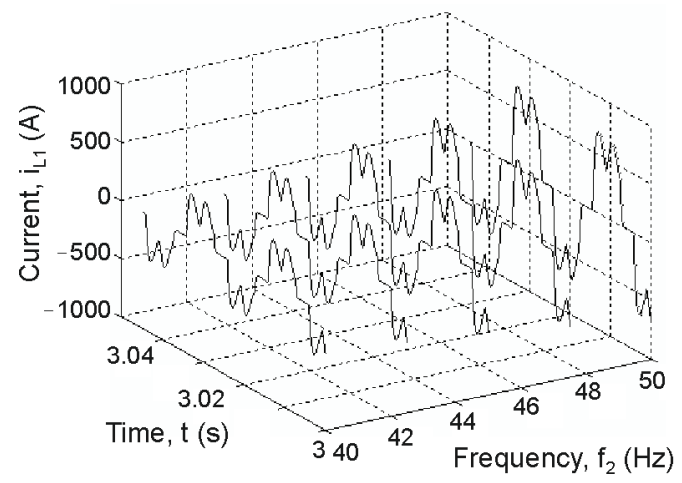

Fig. 11. Part of line current $\mathrm{i}_{\mathrm{L} 1}$ waveforms in cross Section 2

A part of waveforms of currents for the cross section number 2 and the secondary side of the transformer are shown in Figure 11. Note the change of the maximum currents with increasing modulation frequency $f_{2}$. It results from changes in the engine load (without the line reactors in the system).

Table 4. Average values of $T H D_{U}$ and $T H D_{I}$ with respect to the line reactor parameters of the feeding grid and modulating frequency $f_{2}$ for $f_{c}=3.5 \mathrm{kHz}$ in cross Section 2

\begin{tabular}{|c|c|c|c|c|c|c|}
\hline & $\begin{array}{l}f_{2}(\mathrm{~Hz}) \\
\operatorname{Par}_{i}(1)\end{array}$ & 40 & 42.5 & 45 & 47.5 & 50 \\
\hline 0 & $\begin{array}{l}T H D_{U}(\%) \\
T H D_{I}(\%)\end{array}$ & $\begin{array}{c}7.39 \\
39.41\end{array}$ & $\begin{array}{c}8.07 \\
36.67\end{array}$ & $\begin{array}{c}8.84 \\
34.37\end{array}$ & $\begin{array}{c}9.75 \\
32.55\end{array}$ & $\begin{array}{l}10.68 \\
31.09\end{array}$ \\
\hline 1 & $\begin{array}{l}T H D_{U}(\%) \\
T H D_{I}(\%)\end{array}$ & $\begin{array}{c}7.09 \\
37.51\end{array}$ & $\begin{array}{c}7.75 \\
34.98\end{array}$ & $\begin{array}{c}8.48 \\
32.89\end{array}$ & $\begin{array}{c}9.34 \\
31.15\end{array}$ & $\begin{array}{l}10.22 \\
29.73\end{array}$ \\
\hline 2 & $\begin{array}{l}T H D_{U}(\%) \\
T H D_{I}(\%)\end{array}$ & $\begin{array}{c}6.86 \\
35.97 \\
\end{array}$ & $\begin{array}{c}7.49 \\
33.60 \\
\end{array}$ & $\begin{array}{r}8.19 \\
31.65 \\
\end{array}$ & $\begin{array}{l}8.99 \\
29.89 \\
\end{array}$ & $\begin{array}{r}9.86 \\
28.51 \\
\end{array}$ \\
\hline 3 & $\begin{array}{l}T H D_{U}(\%) \\
T H D_{I}(\%)\end{array}$ & $\begin{array}{c}6.69 \\
34.48\end{array}$ & $\begin{array}{l}7.26 \\
32.42\end{array}$ & $\begin{array}{c}7.96 \\
30.49\end{array}$ & $\begin{array}{l}8.74 \\
28.85\end{array}$ & $\begin{array}{c}9.53 \\
27.41 \\
\end{array}$ \\
\hline 4 & $\begin{array}{l}T H D_{U}(\%) \\
T H D_{I}(\%)\end{array}$ & $\begin{array}{c}6.49 \\
33.47\end{array}$ & $\begin{array}{c}7.06 \\
31.37 \\
\end{array}$ & $\begin{array}{c}7.73 \\
29.44\end{array}$ & $\begin{array}{c}8.47 \\
27.84\end{array}$ & $\begin{array}{c}9.23 \\
26.38\end{array}$ \\
\hline
\end{tabular}

Figure 12 presents a part of the phase voltage waveform. Note the impact of the maximum currents (Fig. 11) on the commutation time. It manifests itself in the change in the voltage waveform shape (shown clearly on the top of the waveform e.g. Fig. 12 b).

The motor load is determined under the assumption that it is square relative to the angular speed $\omega$, while the coefficient $A$ determines the relation between the load torque $T_{l}$ and the square of the angular speed of the motor: 


$$
T_{l}=A \omega^{2}[\mathrm{Nm}],
$$

$A$ is a constant, in the considered case equal to 0.08378 (pump 20W39-3/2).

a)

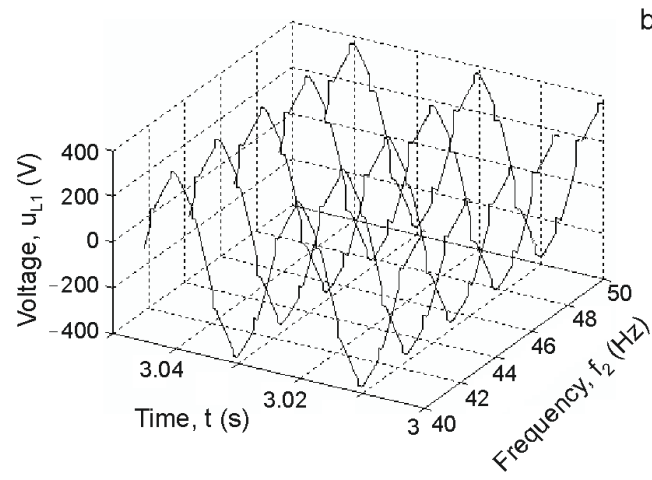

b)

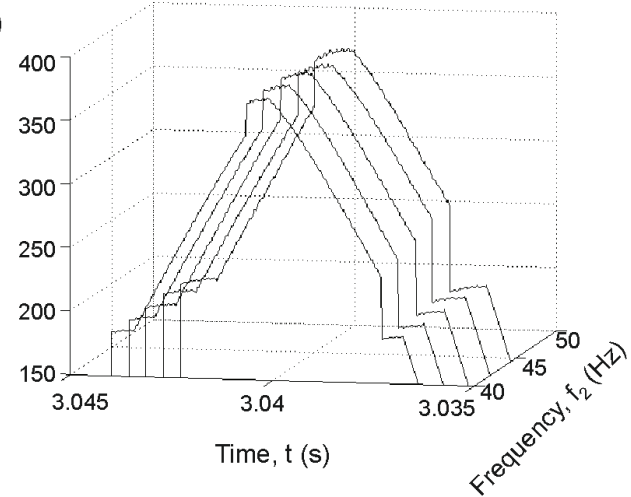

Fig. 12. Part of line to neutral voltage $\mathrm{u}_{\mathrm{L} 1}$ waveforms in cross section 2 (a) and its details (b)

For simulation, the authors assumed that the parameter values of the additional line reactor are taken from standard manufacturer's series [16]. They are presented in Table 2.

Table 4 presents the average values of the coefficients $T H D_{U}$ and $T H D_{I}$ calculated over the three phases for the cross section 2. Figures 13-15 show the values of $T H D_{U}$ for all three cross sections of the system (Fig. 10).

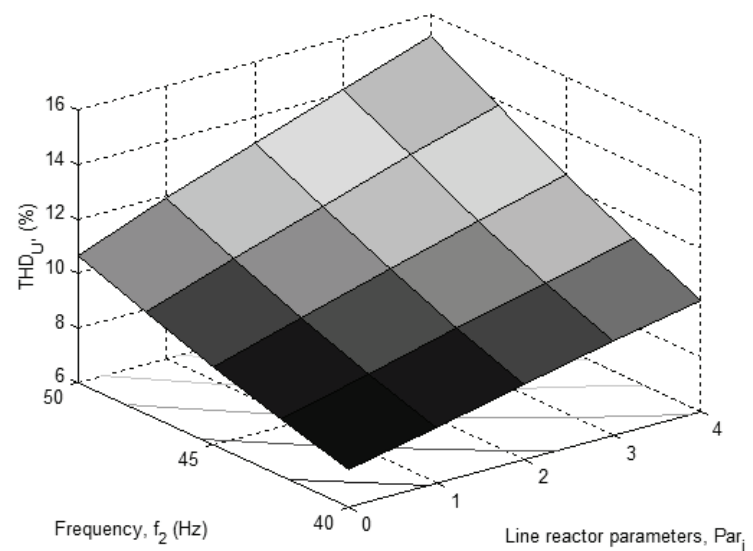

Fig. 13. Relation between $T H D_{U}$ and the modulating frequency $f_{2}$ and line reactor parameters of the feeding grid $\left(f_{c}=3.5 \mathrm{kHz}\right)$ in cross Section 1

The proposed model allows for a comfortable selection of the power system components to reduce the impact of the converter drive on the power grid. From Figures 13-14 we can 
conclude that the $T H D_{U}$ is reduced significantly for the line reactor with the maximum value of inductance and resistance (Table 1). However, the level of this factor in cross Section 2 does not meet the standards [2] for large loads. Nonetheless, in cross Section 3 the $T H D_{U}$ standards are met before converter transformer $\operatorname{Tr}_{\mathrm{CON}}\left(S_{r}=1 \mathrm{MVA}, U_{s c \%}=6 \%\right)$, even in the absence of the line reactors $\left(\operatorname{Par}_{\mathrm{i}}=0\right.$ in Fig. 15).

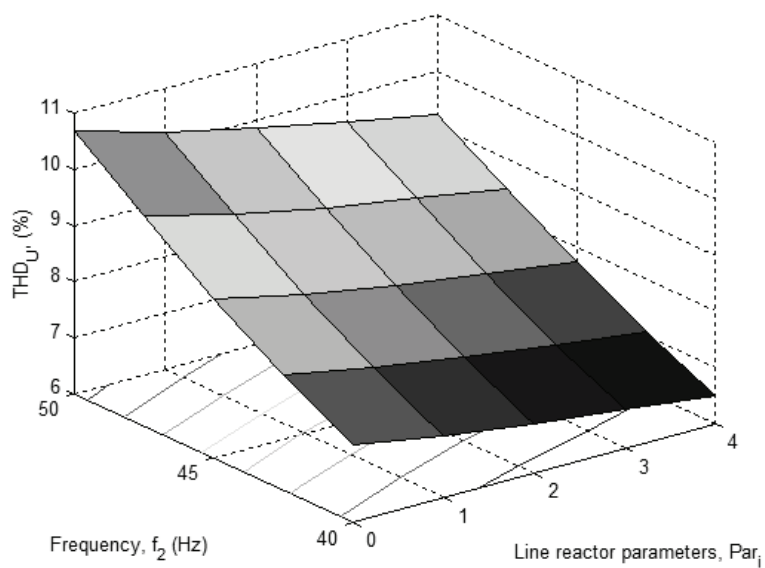

Fig. 14. Relation between $T H D_{U}$ and the modulating frequency $f_{2}$ and the line reactor parameters of the feeding grid $\left(f_{c}=3.5 \mathrm{kHz}\right)$ in the cross Section 2

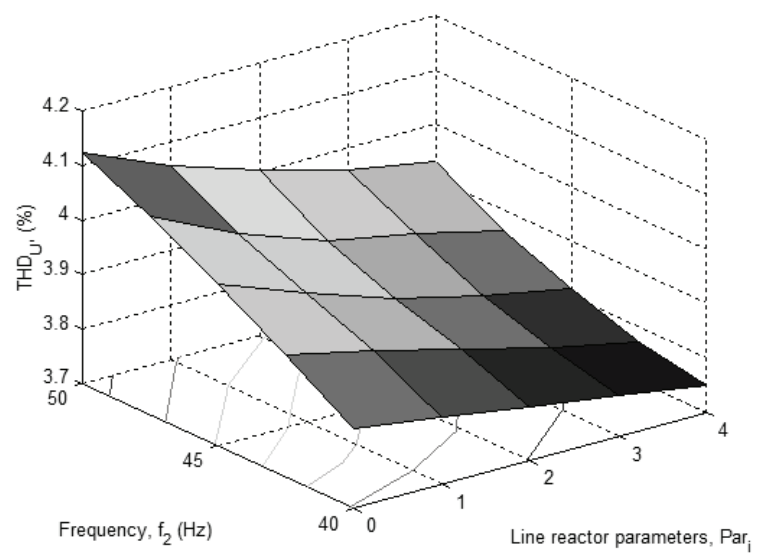

Fig. 15. Relation between $T H D_{U}$ and the modulating frequency $f_{2}$ and the line reactor parameters of the feeding grid $\left(f_{c}=3.5 \mathrm{kHz}\right)$ in cross Section 3

For the current harmonics, assessed with the coefficient $T H D_{I}$, the authors can significantly reduce the value of this coefficient for well-matched line reactors. 


\section{Summary}

This paper presented an application of the formalized variable structure method for modelling of the converter drive system with feeding lines. This method shortens the computational time compared to the steady structure method [6]. The example considered in the paper shows that this method is applicable and very effective both in modelling of power converters and modelling the part of the power grid. This power grid in the proposed model consists of a distribution transformer, converter transformer, line reactors and connecting cables.

The results of simulations and measurements indicate satisfactory accordance. Hence, the authors applied the proposed mathematical model for the calculation in a number of different configurations of the drive system and determination of its impact on the power grid. The model allows to assess the impact of: motor load, feeding lines (e.g., additional line reactors) and drive parameters on the power grid. This allows for an efficient and comfortable selection of the line reactor parameters in order to minimise the current impact of converter drive on the supply grid.

\section{References}

[1] Beniak R., Gardecki A., Multivariate analysis of selected states of the converter drive that allows evaluating efficiency and environmental impact of power electronic part of drive. Electrical Review 87(2): 22-25 (2011).

[2] EN 50160, Voltage characteristics of electricity supplied in public distribution systems. (1999).

[3] EN 61000-3, Electromagnetic compatibility (EMC). (2009).

[4] Kaźmierkowski M.P., Tunia H., Automatic control of converter fed drives. Elsevier, Amsterdam (1994).

[5] Mohan N., Undeland T., Robbins W., Power electronics: converters. Aplications and Design, NY John Wiley Sons (1989).

[6] Beniak R., A formalised variable structure method of modeling converter drives. Electrical Review 3: 83-87 (2009).

[7] Reingold E. M., Nievergelt J., Deo N., Combinatorial Algorithms. Theory and Practice. PrenticeHall, Inc., Englewood Cliffs, New Jersey (1977).

[8] Beniak R., Waindok A., Zimon J., Application of minimization methods in modeling of converter drives. Electrical Review 11: 231-234 (2007).

[9] Gear C.W., Numerical initial value problem in ordinary differential equations. Prentice-Hall Inc., Englewood Cliffs, N.J. (1971).

[10] Chua L.O., Lin P.M., Computer-Aided Analysis of Electronic Circuits: Algorithms and Computational Techniques. Prentice-Hall Inc., Englewood Cliffs, N.J. (1975).

[11] NI 6132/6133 Specifications, http://www.ni.com/pdf//manuals//371231d.pdf

[12] Instruction: VLT 6000 Series Drives for HVAC, www.danfos.com

[13] www.helukabel.pl, accessed 23.04.2011.

[14] www.bitner.com.pl, accessed 15.04.2011.

[15] www.ftz.pl, accessed 15.04.2011.

[16] www.schaffner.com, accessed 23.04.2011. 